\title{
КОМПЛЕКСНЫЕ ИССЛЕДОВАНИЯ ПРОЦЕССА КУЛЬТИВИРОВАНИЯ ХЛЕБОПЕКАРНЫХ ДРОЖЖЕЙ ПРИ ВЫСОКИХ КОНЦЕНТРАЦИЯХ БИОМАССЫ. 1. ИССЛЕДОВАНИЕ ФИЗИЧЕСКИХ СВОЙСТВ СВЕКЛОВИЧНОЙ МЕЛАССЫ
}

\section{Евгения Владимировна Кравцова ${ }^{1}$, Александр Геннадьевич Новоселов ${ }^{2}$, Алексей Александрович Федоров ${ }^{3}$, Сергей Андреевич Сорокин ${ }^{4}$, Екатерина Александровна Фомина ${ }^{5}$, Ольга Александровна Суздальцева ${ }^{6}$}

\author{
1, 2, 3, 4, 5, 6 Университет ИТМО, Санкт-Петербург, Россия \\ 1 evkravtcova@itmo.ru, https://orcid.org/0000000313933347 \\ 2 agnovoselov@itmo.ru, https://orcid.org/0000000211685362 \\ 3 aafedorov@itmo.ru, https://orcid.org/0000000338607708 \\ ${ }^{4}$ sorokinsa@itmo.ru, https://orcid.org/0000000156646132 \\ 5 catunya.fomka@yandex.ru, https://orcid.org/0000000322363745 \\ 6 olya.sorokina.2010@gmail.com, https://orcid.org/000000031745073X
}

Аннотация. Рассмотрены пути повышения эффрективности дрожжевых заводов. Показаны возможность и эффрективность проведения процесса культивирования хлебопекарных дрожжей при высоких концентрациях биомассы до 500 ке/м³ в кожухотрубном струйно-инжекционном ферментаторе. Дано сравнение технико-экономических показателей процесса культивирования традиционным и предлагаемым способами. Представлена взаимосвязь коэффрициентов молекулярного переноса импульса, теплоты и массы, а именно коэффрициента кинематической вязкости, коэффрициента температуропроводности и коэффрициента молекулярной диффрузии. Выполнен анализ опубликованных в научно-технической литературе данных по комплексному изучению динамической вязкости водных растворов мелассы в случае использования культивирования дрожжей при высокой концентрации биомассы. Цель данной работы: провести комплексные исследования фризических свойств водного раствора мелассы для выбранного диапазона температур и концентраций. В работе представлены результаты экспериментальных исследований коэфффициента динамической вязкости, позволяющие проследить характер течения водных растворов мелассы при различном содержании сухих веществ в диапазоне изменения температур

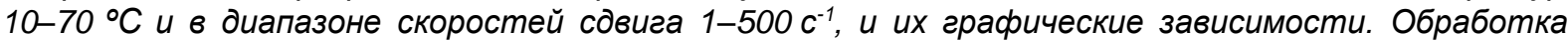
экспериментальных данных, полученных в результате измерения вязкости мелассных растворов при помощи вискозиметра Rheotest RN 4.1. и вискозиметра Гепплера, позволила определить численные значения коэффрициентов динамической вязкости и их математической интерпретации в зависимости от концентрации сухих веществ при различных температурах. Значения, полученные на данных приборах, позволили предположить, что в результате эксперимента приборы дают схожие, а, следовательно, достоверные результаты.

Ключевые слова: культивирование хлебопекарных дрожжей, струйно-инжекционного ферментатор, высокая концентрация биомассы дрожжей, водный раствор мелассы, вязкость раствора мелассы, концентрация сухих веществ, измерение вязкости, динамическая вязкость, коэфффициент молекулярного переноса импульса, течение водных растворов.

Для цитирования: Комплексные исследования процесса культивирования хлебопекарных дрожжей при высоких концентрациях биомассы. Исследование физических свойств свекловичной мелассы / А. Г. Новоселов [и др.]. // Ползуновский вестник. 2021. № 3. С. 42-53.doi: 10.25712/ ASTU.2072-8921.2021.03.006.

(с) Кравцова, Е. В., Новоселов, А. Г., Федоров, А. А., Сорокин, С. А., Фомина, Е. А., Суздальцева, О. А., 2021 
Original article

\title{
COMPLEX STUDIES OF CULTIVATION PROCESS OF BAKER'S YEAST WITH HIGH CONCENTRATIONS OF BIOMASS. 1. INVESTIGATION OF PHYSICAL PROPERTIES OF BEET MOLASSES
}

\author{
Evgeniya V. Kravtsova ${ }^{1}$, Aleksandr G. Novoselov ${ }^{2}$, Aleksey A. Fedorov ${ }^{3}$, \\ Sergey A. Sorokin ${ }^{4}$, Ekaterina A. Fomina ${ }^{5}$, Olga A. Suzdaltseva ${ }^{6}$ \\ 1, 2, 3, 4, 5, 6 ITMO University, St. Petersburg, Russia \\ 1 evkravtcova@itmo.ru, https://orcid.org/0000000313933347 \\ 2 agnovoselov@itmo.ru, https://orcid.org/0000000211685362 \\ ${ }^{3}$ aafedorov@itmo.ru, https://orcid.org/0000000338607708 \\ ${ }^{4}$ sorokinsa@itmo.ru, https://orcid.org/0000000156646132 \\ ${ }^{5}$ catunya.fomka@yandex.ru, https://orcid.org/0000000322363745 \\ 6 olya.sorokina.2010@gmail.com, https://orcid.org/000000031745073X
}

Abstract. The ways of increasing the efficiency of yeast factories are considered. The possibility and efficiency of the process of cultivation of baker's yeast at high concentrations of biomass up to $500 \mathrm{~kg} / \mathrm{m}^{3}$ in a shell-and-tube jet-injection fermenter are shown. Comparison of technical and economic indicators of the cultivation process by traditional and proposed methods is given. The relationship between the coefficients of molecular transfer of momentum, heat and mass, namely, the coefficient of kinematic viscosity, the coefficient of thermal diffusivity, and the coefficient of molecular diffusion is presented. The analysis of the data published in the scientific and technical literature on the complex study of the dynamic viscosity of aqueous solutions of molasses in the case of using the cultivation of yeast at a high concentration of biomass was carried out. The purpose of this work is to conduct a comprehensive study of the physical properties of an aqueous solution of molasses for the selected range of temperatures and concentrations. The paper presents the results of experimental studies of the dynamic viscosity coefficient, which make it possible to trace the nature of the flow of aqueous molasses solutions at different contents of dry substances in the temperature range of 10-70 ${ }^{\circ} \mathrm{C}$ and in the shear rate range of 1-500 s-1, and their graphical dependences. Processing of experimental data obtained by measuring the viscosity of molasses solutions using a Rheotest RN 4.1 viscometer. and the Heppler viscometer, made it possible to determine the numerical values of the $d y$ namic viscosity coefficients and their mathematical interpretation depending on the concentration of dry substances at different temperatures. The values obtained with these devices allowed us to assume that, as a result of the experiment, the devices give similar, and, therefore, reliable results.

Keywords: cultivation of baker's yeast, jet-injection fermenter, high concentration of yeast biomass, aqueous solution of molasses, viscosity of molasses solution, concentration of solids, measurement of viscosity, dynamic viscosity, molecular momentum transfer coefficient, flow of aqueous solutions.

For citation: Kravtsova, E.V., Novoselov, A.G., Fedorov, A.A., Sorokin, S.A., Fomina, E.A. \& Suzdaltseva, O.A. (2021). Complex studies of cultivation process of baker's yeast with high concentrations of biomass. 1. Investigation of the physical properties of beet molasses. Polzunovskiy vestnik, (3), 42-53. (In Russ.). doi: 10.25712/ASTU.2072-8921.2021.03.006.

\section{ВВЕДЕНИЕ}

Анализ современных тенденций в области производства высококачественных и экологически чистых продуктов питания, лекарственных препаратов, парфюмернокосметических средств, комбикормов показывает, что немаловажную роль и интенсивное развитие получили отрасли промышленности, в состав технологического процесса которых входят биосорбционные процессы, в частности микробиологическая промышленность [1].

Наиболее широко биосорбционные процессы нашли применение в производстве хлебопекарных и кормовых дрожжей. Учиты- 


\section{Е. В. КРАВЦОВА, А. Г. НОВОСЕЛОВ, А. А. ФЕДОРОВ, С. А. СОРОКИН,}

Е. А. ФОМИНА, О. А. СУЗДАЛЬЦЕВА

вая несомненную общность аэробного процесса культивирования одноклеточных микроорганизмов, остановимся на наиболее развитой в плане существующего промышленного потенциала - хлебопекарной дрожжевой промышленности [2].

В настоящее время средний выход хлебопекарных дрожжей с единицы субстрата невысок и составляет около 70 \%. Причина таких невысоких выходов продукции лежит в низких массообменных характеристиках ферментаторов, которые определяются в первую очередь их конструкцией. Потребность в дрожжах вырастает из года в год, поэтому увеличение производительности дрожжевых заводов - задача важная и необходимая, и решена она может быть как за счет модернизации оборудования, так и совершенствования технологии производства [2].

Мощность дрожжевого завода по целевому продукту может быть укрупненно оценена по известной зависимости [2]:

$$
N=\frac{\left(K \cdot X \cdot V_{p} \cdot n\right)}{\left(\tau-\tau_{n}\right)},
$$

где $\mathrm{N}$ - мощность завода по целевому продукту, кг/год;

К - коэффрициент, учитывающий средний выход целевого продукта, а также величину брака и заполнения ферментаторов культуральной жидкостью;

$V_{p}$ - рабочий объем ферментаторов, м;

$X$ - концентрация дрожжей в культу-

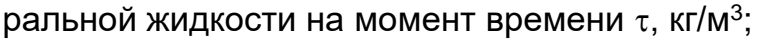
$n$ - число рабочих дней в году;

$\tau$ - продолжительность культивирования, сутки;

$\mathrm{T}_{\mathrm{n}}$ - продолжительность подготовительных операций на один цикл культивирования, сутки.

Из уравнения (1) видно, что мощность производства по выпуску дрожжей может быть увеличена за счет увеличения количества ферментаторов или их суммарного рабочего объема на последней стадии культивирования, т.е. $V_{p}$, повышения концентрации биомассы $X$ и интенсификации клеточного роста, что выражается в снижении времени культивирования т. Увеличение $V_{p}$ ведет к дополнительным капитальным вложениям, увеличению энергозатрат и вспомогательных материалов, связанных с мойкой и техническим обслуживанием ферментаторов. Кроме того, возрастает и время $\tau_{n}$ на подготовительные работы.

Так, при культивировании хлебопекарных дрожжей в ферментаторе с геометрическим объемом $100 \mathrm{~m}^{3}$ до концентрации $X_{k}=90 \mathrm{\kappa г} / \mathrm{M}^{3}$ и конечном рабочим объемом 44
$V_{p}=50$ м $^{3}$ можно получить 4,5 тонны дрожжей с содержанием $25 \%$ CB.

В тоже время аналогичное количество биомассы можно получить при культивировании в аппарате с $V_{p}=30 \mathrm{~m}^{3}$ до $X_{k}=450 \mathrm{\kappa г} / \mathrm{m}^{3}$ и конечном объеме $V_{p}=10 \mathrm{~m}^{3}[3,4]$.

Перспектива повышения конечной концентрации дрожжей, т.е. проведение культивирования одноклеточных микроорганизмов при высокой концентрации их в ферментаторе на всех стадиях технологического процесса, - неоспорима: высвобождается производственная площадь, уменьшаются затраты энергии и воды на проведение процесса, пара и моющих средств на стерилизацию внутренней поверхности ферментатора и ее мойку. Кроме того, проведение культивирования до $X_{k}=400-500 \mathrm{\kappa} / \mathrm{m}^{3}$ позволит сократить число стадий сепарации, уменьшить потери биомассы при проведении этого процесса, а высокое содержание дрожжевых клеток в единице объема культуральной жидкости само по себе препятствует развитию посторонней микрофрлоры в среде [5]. Более того, такое проведение процесса целесообразно и с экологической точки зрения, поскольку уменьшается объем стоков, подлежащих очистке.

На базе Университета ИТМО были проведены комплексные исследования возможности культивирования хлебопекарных дрожжей при высоких концентрациях биомассы и разработана конструкция кожухотрубного струйно-инжекционного ферментатора (КСИФ), представленного на рисунке 1 , позволяющая успешно реализовывать данную технологию.

Принцип его работы заключается в образовании и движении газожидкостной смеси в трубах аппарата за счет инжектирующей способности свободной струи жидкости, вытекающей из сопла определенной фрормы, ее динамического воздействия на смесь в нисходящем потоке и газлифтного эффекта в восходящем [6, 7, 8]. Конструктивно КСИА состоит из двух аппаратов: теплообменникааэратора 1 и емкости-накопителя 2. Теплообменник-аэратор (Т-А) представляет собой вертикальный кожухотрубный теплообменник с видоизмененной верхней частью. Он состоит из вертикальных опускных 4, подъемных 5 и сливных 6 труб, последовательно соединенных между собой и образующих циркуляционный канал. Верхняя часть Т-А, присоединенная к его кожухотрубной части, разделена горизонтальной перегородкой с образованием жидкостной 10 и газовой 9 камер. В свою очередь газовая камера 9 разделена на две части вертикальной перегородкой 17 с ПОЛЗУНОВСКИЙ ВЕСТНИК № 32021 


\section{КОМПЛЕКСНЫЕ ИССЛЕДОВАНИЯ ПРОЦЕССА КУЛЬТИВИРОВАНИЯ ХЛЕБОПЕКАРНЫХ ДРОЖЖЕЙ ПРИ ВЫСОКИХ КОНЦЕНТРАЦИЯХ БИОМАССЫ. \\ 1. ИССЛЕДОВАНИЕ ФИЗИЧЕСКИХ СВОЙСТВ СВЕКЛОВИЧНОЙ МЕЛАССЫ}

образованием основной 16 и дополнительной камер. В горизонтальной перегородке верхней камеры установлены сопла: основные 7 и дополнительные 8. Основные сопла 7 размещаются в основной газовой камере 16 строго вертикально над опускными трубами 4 соосно с ними. Дополнительные сопла 8 размещены в дополнительной газовой камере 9 над сливными трубами 6 соосно с ними. Основная газовая камера 16 имеет патрубки для подачи воздуха (газа) 15 [3].

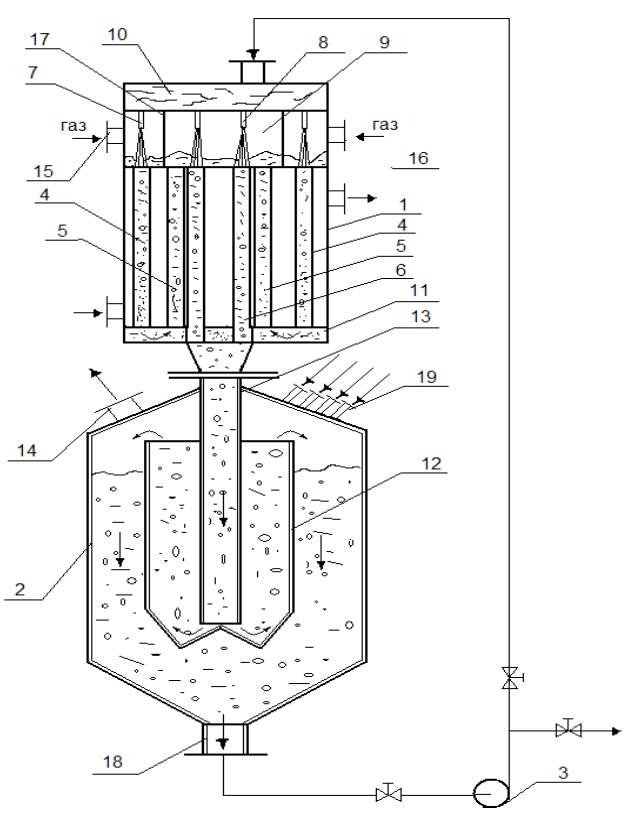

Рисунок 1 - Конструкция струйно-инжекционного ферментатора

Figure 1 - Design of a jet-injection fermenter

Емкость-накопитель (Е-Н) 2 представляет собой вертикальный цилиндроконический резервуар, состоящий из корпуса 2, центральной трубы 13 и циркуляционного стакана 12, размещенных внутри корпуса 2 соосно с ним. В коническом днище Е-Н размещен патрубок 18, соединенный с всасывающим трубопроводом циркуляционного насоса 3.

Центральная труба 13 в верхней части соединена с Т-А, а нижней частью входит внутрь циркуляционного стакана 12, не соединяясь с его днищем [3].

Циркуляционный стакан 12 также размещен соосно корпусу 2 и имеет двухконусное днище. В самых нижних точках конусного ребра изготовлены отверстия для слива культуральной жидкости из циркуляционного стакана при опорожнении КСИФа.

Для отвода отработанного воздуха в верхней части Е-Н размещен патрубок 14. Здесь же размещены все необходимые технологические патрубки 19 для подачи питательных и ростовых веществ, а также химического пеногасителя.

Культивирование хлебопекарных дрожжей в КСИФе проводится в следующей последовательности: в подготовленный к работе ферментатор через технологические патрубки 19 вводится вода, водные растворы мелассы, питательных солей и ростовых веществ в соответствии с технологическим режимом культивирования. Затем запускается циркуляционный насос 3, и субстрат циркулирует по объему КСИФ до достижения заданной температуры и рН. После этого вводится засевной материал (чистая культура дрожжей Saccharomyciescerevisiae) и начинается собственно процесс культивирования.

Культуральная жидкость совершает циркуляционное движение по трубам Т-А и каналам Е-Н, где за исключением последней стадии идет постоянный перенос кислорода от пузырьков воздуха к клеткам в сильно турбулизованном режиме. Подача субстрата ростовых веществ и питательных солей осуществляется в емкость-накопитель.

Проведенный анализ известных конструкций ферментаторов, применяемых в пищевой, микробиологической и химической промышленности (таблица 1), показал, что конструкция кожухотрубного струйно- 
инжекционного аппарата (КСИА) имеет значительные преимущества.

К основным преимуществам фрерментаторов данной конструкции следует отнести:

- высокие тепло, массообменные характеристики;
- отсутствие необходимости в воздухонагнетательном оборудовании;

- возможность проведения процесса при высоких концентрациях биомассы и кратности разбавления мелассы;

Таблица 1 - Сравнительный анализ известных конструкций ферментаторов

Table 1 - Comparative analysis of known fermenter designs

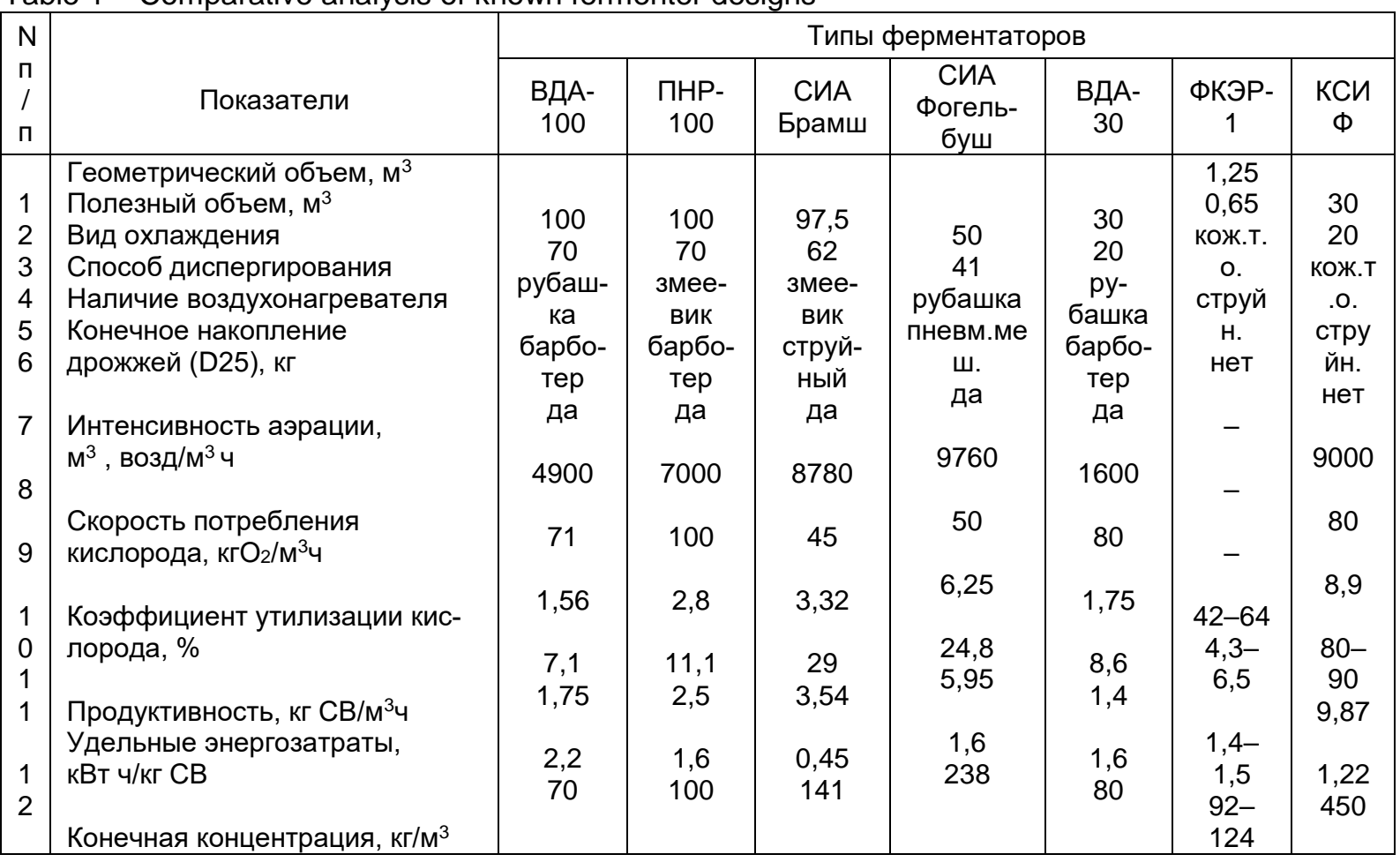

Однако перевод технологий производства дрожжей на их культивирование при высоких концентрациях биомассы требует более глубоких и детальных исследований. В частности, новая технология культивирования требует бесперебойного обеспечения клеток питательными и ростовыми веществами, растворенным кислородом, а также своевременным отводом газообразных продуктов метаболизма от них. Кроме того, в процессе метаболизма клеток, в результате целого комплекса экзотермических реакций, происходящих внутри клетки, выделяется большое количество тепловой энергии, которую необходимо отводить из культуральной жидкости, т.к. повышение температуры выше $34{ }^{\circ} \mathrm{C}$ приводит к снижению скорости роста самих клеток.

Указанные обстоятельства заставляют задуматься над тем, что нельзя провести культивирование при высоких концентрациях биомассы в обычных, применяемых на заводах барботажных аппаратах, основное досто- инство которых заключается в простоте и надежности.

При аэробном культивировании микроорганизмов необходимо учитывать, что концентрация биомассы в процессе культивирования будет постоянно возрастать и, следовательно, массовые потоки питательных веществ и растворенного кислорода из окружающей среды тоже должны возрастать [9].

В процессе метаболизма увеличивающегося числа клеток неизбежно будет увеличиваться и количество отводимого, выделяемого клетками в жидкостную среду, растворенного диоксида углерода, который, в дальнейшем, диффундируя через нее в воздушные пузырьки, удаляется из фрерментатора. Массовые потоки кислорода, потребляемого клетками и выделяемого клетками диоксида углерода, примерно равны в рассматриваемый час культивирования [10].

Как видно из вышеизложенного, механизм переноса тепловой энергии и массы во многом зависит от гидродинамической обста- 


\section{КОМПЛЕКСНЫЕ ИССЛЕДОВАНИЯ ПРОЦЕССА КУЛЬТИВИРОВАНИЯ ХЛЕБОПЕКАРНЫХ ДРОЖЖЕЙ ПРИ ВЫСОКИХ КОНЦЕНТРАЦИЯХ БИОМАССЫ. \\ 1. ИССЛЕДОВАНИЕ ФИЗИЧЕСКИХ СВОЙСТВ СВЕКЛОВИЧНОЙ МЕЛАССЫ}

новки в рабочем объеме. Основное сопротивление скоростям переноса массы и тепловой энергии, на молекулярном уровне, лежит в жидкостной фразе, а степень влияния на скорости переноса - от степени интенсивности ее турбулизации [11].

В общем случае, на поверхности разделяющих фаз, будь то твердая фаза или газовая фраза, практически всегда существуют пограничные слои, в которых наблюдается отсутствие турбулентности (ламинарные пограничные слои). Толщина этих слоев может быть соизмерима с размерами молекул, в зависимости от степени турбулизации той или иной фазы. Например, в пристенной области внутренней поверхности корпуса барботажного аппарата или теплопередающей поверхности, встроенных в рабочий объем, элементов трубчатых или змеевиковых теплообменников. Даже у поверхности пузырьков газовой фразы существует слой жидкостной фазы, обусловленный наличием поверхностного натяжения жидкости, окружающей объем заключенного в пузырьке газа. Это явление подтверждается многочисленными эмпирическими уравнениями, в которых, как правило, вводятся параметры, учитывающие толщины ламинарного пограничного подслоя, теплового подслоя или диффузионного подслоя. Наличие этих слоев предполагает, что перенос количества движения (импульса), тепловой энергии и массы целевого компонента существенно ниже, чем в основном объеме рабочей среды, и происходит по механизмам молекулярного переноса, т. е. вязкого трения, температуропроводности и молекулярной дифффузии.

Процесс молекулярного переноса количества движения в условиях ламинарного режима может быть представлен в виде уравнения [12]

$$
\tau=-\vartheta \frac{d\left(\overline{U_{x}} \cdot \rho\right)}{d y},
$$

где т - касательные напряжения или напряжение сдвига, H/M²; $\overline{U_{x}}$ - осредненная по времени локальная скорость жидкости в направлении $\mathrm{x}$, м/с; $y$ - значения координат соседних слоев, взятых по направлению перпендикулярному к направлению движения слоев х, м; $\rho$ - плотность жидкости, кг/м3; $\vartheta-$ кинематическая вязкость жидкости, $\mathrm{M}^{2} / \mathrm{c}$.

Процесс молекулярного переноса тепловой энергии в аналогичных условиях

$$
q=-a \frac{d\left(C_{p} \cdot \rho \cdot T\right)}{d y}=\frac{\lambda}{C_{p} \rho} \frac{d\left(C_{p} \cdot \rho \cdot T\right)}{d y}
$$

где $q$ - плотность теплового потока, Дж/(c' $\left.{ }^{\cdot} 2\right)$;

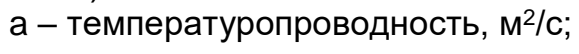

$C_{p}$ - изобарная теплоемкость жидкости, Дж/(кг К);

$\lambda$ - теплопроводность, Дж/(c· $`$ КК);

Т - температура, К.

Аналогично, процесс молекулярного переноса массы компонента А в жидкости В

$$
m_{A}=-D_{A B} \frac{d C_{A}}{d y},
$$

где $m_{A}$ - плотность массового потока вещества А в жидкости $\mathrm{B}$; моль/(с' $\left.\mathrm{m}^{2}\right) D_{A B}-$ коэффициент молекулярной диффузии вещества А в жидкости $\mathrm{B}, \mathrm{M}^{2} / \mathrm{c} ; C_{A}$ - концентрация вещества А в жидкости $\mathrm{B}$, моль/ $\mathrm{M}^{3}$.

Анализируя уравнения (2-4), можно увидеть, что, несмотря на описываемые ими физические процессы принципиально различны, форма уравнений переноса одинаковая, а коэффициенты молекулярного переноса $v$, a и $D_{A B}$ имеют одну и ту же размерность [13]. С другой стороны, вполне очевидно, что вышеупомянутые коэфрфициенты молекулярного переноса являются константами для жидкостей с постоянным химическим составом во времени $t$, температуре $\mathrm{T}$ и давлении Р. Изменение любого из этих параметров или нескольких одновременно приводит к изменению либо химического состава (например, в процессах массопереноса), либо к изменению термодинамического состояния молекул жидкости (например, в гидродинамических и тепловых процессах), что неизбежно отразится на фризико-химических свойствах данной жидкости, а, следовательно, на численных значениях $v$, а и $D_{A B}$. Известных значений коэффициентов молекулярного переноса в существующей литературе [9, 12, 14] приведено очень мало, к тому же значения коэффрициента кинематической вязкости не связаны со скоростью сдвига, а значения коэффициента молекулярной диффузии растворенных кислорода и диоксида углерода в водных растворах мелассы, питательных солей и ростовых веществ и отсутствуют вовсе.

Решение этой задачи позволяет более обоснованно подойти к расчетам коэффицциентов молекулярной диффузии $\mathrm{CO}_{2}$ и $\mathrm{O}_{2}$ в питательных средах для проведения массообменных расчетов аппаратов, предназначенных для воспроизводства биомассы в дрожжевой промышленности [9].

Перенос кислорода из газовой фразы (воздуха) к клетке и отвод диоксида углерода от клетки, а также тепловой энергии происходит через жидкую питательную среду, разделяющую газовую (пузырьки воздуха) и квазитвердую (клетки) фразы. Именно в ней сосредоточено основное сопротивление и теплопереносу, и массопереносу. 


\section{МЕТОДЫ ИССЛЕДОВАНИЯ}

Для дрожжевого производства в качестве питательной среды используются водные растворы мелассы с добавлением питательных солей. Очевидно, чем больше молекул «посторонних» веществ в воде, тем сильнее сказывается их присутствие в растворах на изменение скорости дифффузии по отношению к скорости дифффузии в «чистой» воде
[15]. В связи с тем, что количество питательных веществ в водном растворе (жидкостной фразе) неизбежно возрастет, то очевидно, что изменятся и ее фииико-химические свойства.

В этой связи встала необходимость проведения комплексных исследований влияния химического состава питательной среды на коэфффициенты переноса в широком диапазоне температур и концентраций мелассы, питательных солей и ростовых веществ [15].

Таблица 2 - Химический состав и некоторые свойства мелассы

Table 2 - Chemical composition and some properties of molasses

\begin{tabular}{|c|c|c|c|}
\hline Показатель & Минимум & Максимум & $\begin{array}{c}\text { Оптимум для культивирования } \\
\text { дрожжей }\end{array}$ \\
\hline \multicolumn{4}{|l|}{ 1. Содержание, \% } \\
\hline - сухие вещества (СВ) & 61 & 86 & 74 \\
\hline $\begin{array}{c}\text { - содержание сахара по поляримет- } \\
\text { ру }\end{array}$ & 40 & 54 & $46 \ldots 50$ \\
\hline - инвертный сахар & 0,1 & 10 & не более 2 \\
\hline - рафрфиноза & - & 3 & не более 1 \\
\hline \multicolumn{4}{|c|}{ 2. Сумма сбраживаемых сахаров, \% } \\
\hline - Общая сумма, $\Sigma$ & 40 & 57 & $46 \ldots 50$ \\
\hline - доброкачественность $\left(\frac{\sum 100}{C B}\right)$ & 56 & 75 & не менее 55 \\
\hline - зола (без кальция) & 4 & 12 & не менее 7 \\
\hline$-\mathrm{K}_{2} \mathrm{O}$ & 1 & 5,5 & 3,5 \\
\hline$-\mathrm{MgO}$ & 0,001 & 1 & - \\
\hline$-\mathrm{CaO}$ & 0,1 & 3 & не более 1 \\
\hline$-\mathrm{Na}_{2} \mathrm{O}_{4}$ & 1 & 1,4 & - \\
\hline \multicolumn{4}{|c|}{ 3. Азот, \% } \\
\hline - общий & 0,5 & 2,3 & не менее 1,4 \\
\hline - аминный (до гидролиза) & 0,1 & 0,6 & не менее 0,3 \\
\hline - аминный (после гидролиза) & 0,3 & 1,8 & не менее 0,35 \\
\hline \multicolumn{4}{|c|}{ 4. Летучие кислоты, \% } \\
\hline $\mathrm{SO}_{2}$ & 0,01 & 0,07 & 0,05 \\
\hline
\end{tabular}

В данной статье представлены результаты исследования фризических свойств водных растворов свекловичной мелассы. Свекловичная меласса является побочным продуктом сахарных производств. Химический состав и некоторые свойства мелассы представлен в таблице 2 [15].

\section{РЕЗУЛЬТАТЫ И ИХ ОБСУЖДЕНИЕ}

В исследовании использовалась меласса, полученная с КПП г. Санкт-Петербург. Концентрация сухих веществ в исходном образце определялась при помощи ресрактометра и составляла $77,7 \%$. Из исходного образца было приготовлено 5 растворов различной концентрации в диапазоне от 15 до $60 \%$ СВ путем разбавления дистиллированной водой. Массы мелассы и воды для приготовления растворов заданной концентрации

определялись в соответствии со следующими фрормулами:

$$
\begin{aligned}
m_{\mathrm{B}}= & \frac{V \cdot \rho_{\mathrm{M}} \cdot\left(w_{1}-w_{2}\right)}{\rho_{\mathrm{M}} \cdot w_{1} / \rho_{\mathrm{B}}-\rho_{\mathrm{M}} \cdot w_{2} / \rho_{\mathrm{B}}+w_{2}}, \\
& m_{\mathrm{M}}=\left(V-m_{\mathrm{B}} / \rho_{\mathrm{B}}\right) \rho_{\mathrm{M}},
\end{aligned}
$$

где $\mathrm{m}_{\mathrm{B}}$ - масса дистиллированной воды, г; mм - масса мелассы исходной концентрации, г; V - требуемый объем получаемого раствора, мл; $\rho_{м}$ - плотность мелассы исход-

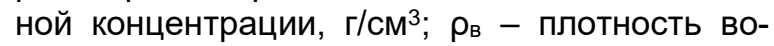

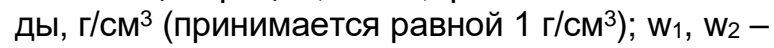
исходная и конечная массовые доли CB.

Содержание сухих веществ в полученных растворах контролировалось при помощи рефрактометра. Плотность исходного образца и растворов определялась с использованием ареометров.

Для измерения вязкости растворов всех концентраций использовался вискозиметр с падающим шариком HÖPPLER® KF 3.2. Измерения проводились в температурном диа- 


\section{КОМПЛЕКСНЫЕ ИССЛЕДОВАНИЯ ПРОЦЕССА КУЛЬТИВИРОВАНИЯ ХЛЕБОПЕКАРНЫХ ДРОЖЖЕЙ ПРИ ВЫСОКИХ КОНЦЕНТРАЦИЯХ БИОМАССЫ. \\ 1. ИССЛЕДОВАНИЕ ФИЗИЧЕСКИХ СВОЙСТВ СВЕКЛОВИЧНОЙ МЕЛАССЫ}

пазоне 10-80 C. Перед каждым экспериментом проба, залитая в опускную трубу вискозиметра, термостатировалась в течение 20 минут для достижения заданной температуры. Каждый эксперимент при заданной температуре включал в себя 5 опытов, по результатам которых определялось среднее время падения шарика в пробе.

Кроме того, для образцов с концентрацией СВ 60,2 \% и 77,7 \% были проведены эксперименты по измерению вязкости на ротационном вискозиметре Rheotest RN 4.1. Измерения проводились в температурном диапазоне $10-70{ }^{\circ} \mathrm{C}$ и в диапазоне скоростей сдвига 1-500 c-1. Для каждого эксперимента в измерительную ячейку отбиралась проба объемом 30 мл, после чего термостатировалась в течение 20 минут для достижения заданной температуры. Время одного экспери- мента составляло 10 минут - по 1 минуте на каждое значение скорости сдвига.

На основе данных, полученных в результате измерений, были построены следующие графические зависимости: кривые течения, вязкостно-температурные кривые и кривые зависимости коэффициента динамической вязкости от скорости сдвига для растворов с концентрацией сухих веществ 60,2 \% и 77,7 \%, а также зависимость вязкости от содержания сухих веществ при различных температурах.

На рисунке 2 представлена зависимость напряжения сдвига от скорости сдвига при различных температурах для раствора с концентрацией сухих веществ 60,2%. Как видно из графика, данная зависимость является линейной и проходит через начало координат, что характеризует данный раствор мелассы как ньютоновскую жидкость.

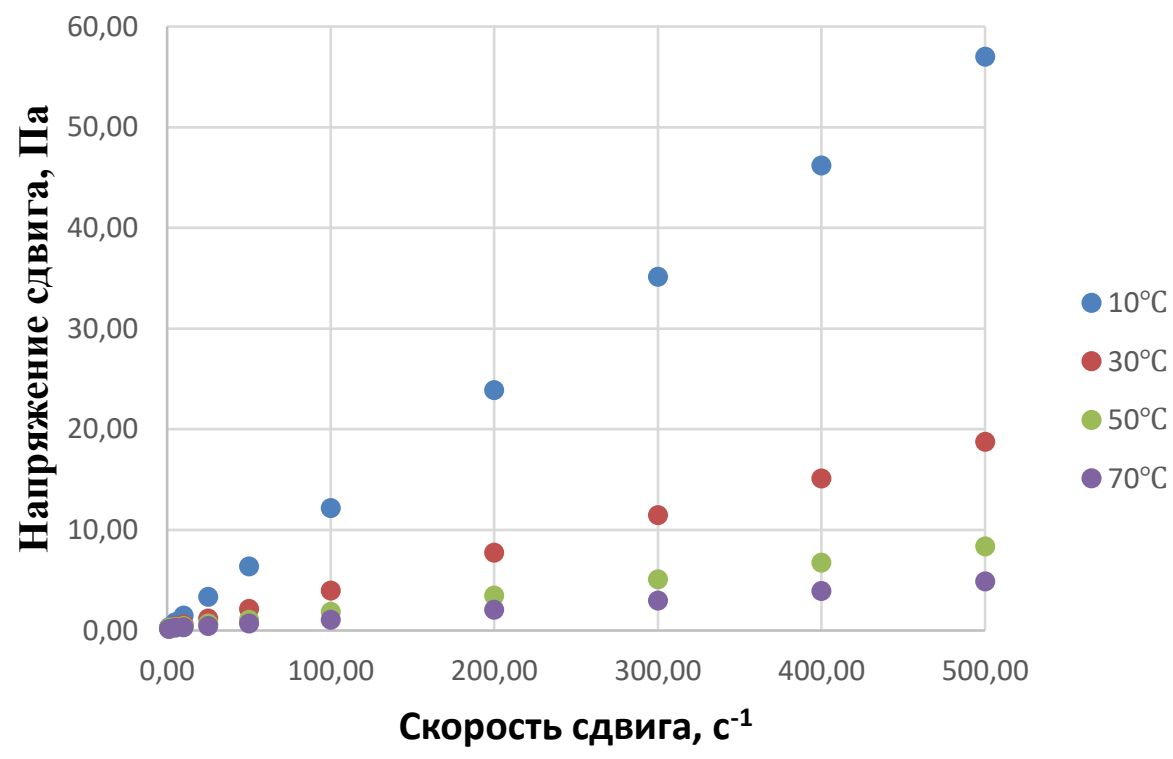

Рисунок 2 - Зависимость напряжения сдвига от скорости сдвига при различных температурах для раствора с концентрацией сухих веществ 60,2 \%

Figure 2 - Dependence of shear stress on shear rate at different temperatures for a solution with a dry matter concentration of $60.2 \%$

Рисунок 3 иллюстрирует зависимость вязкости раствора мелассы с содержанием
СВ 60,2 \% от скорости сдвига при различных температурах. 
Е. В. КРАВЦОВА, А. Г. НОВОСЕЛОВ, А. А. ФЕДОРОВ, С. А. СОРОКИН, Е. А. ФОМИНА, О. А. СУЗДАЛЬЦЕВА

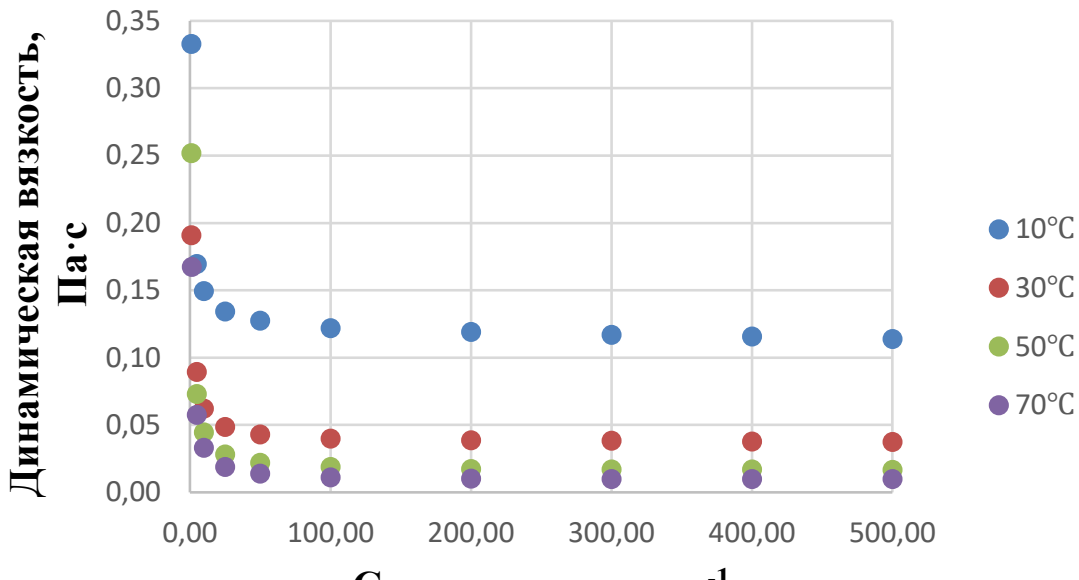

Скорость сдвига, $\mathrm{c}^{-1}$

Рисунок 3 - Зависимость вязкости раствора мелассы с содержанием СВ 60,2 \% от скорости сдвига при различных температурах

Figure 3 - Dependence of the viscosity of a molasses solution with a DM content of $60.2 \%$ on the shear rate at different temperatures

Вязкость снижается с увеличением скорости сдвига от $1 \mathrm{c}^{-1}$ до $50 \mathrm{c}^{-1}$, при дальнейшем его увеличении значение коэфрфициента динамической вязкости остается практически постоянным. Таким образом, раствор при низких значениях скорости сдвига ведет себя как псевдопластичная жидкость, а при скоро- стях выше $50 \mathrm{c}^{-1}$ - как ньютоновская жидкость.

Рисунок 4 показывает зависимость величины коэфффициента динамической вязкости от температуры при различных скоростях сдвига. С ростом температуры вязкость мелассы снижается.

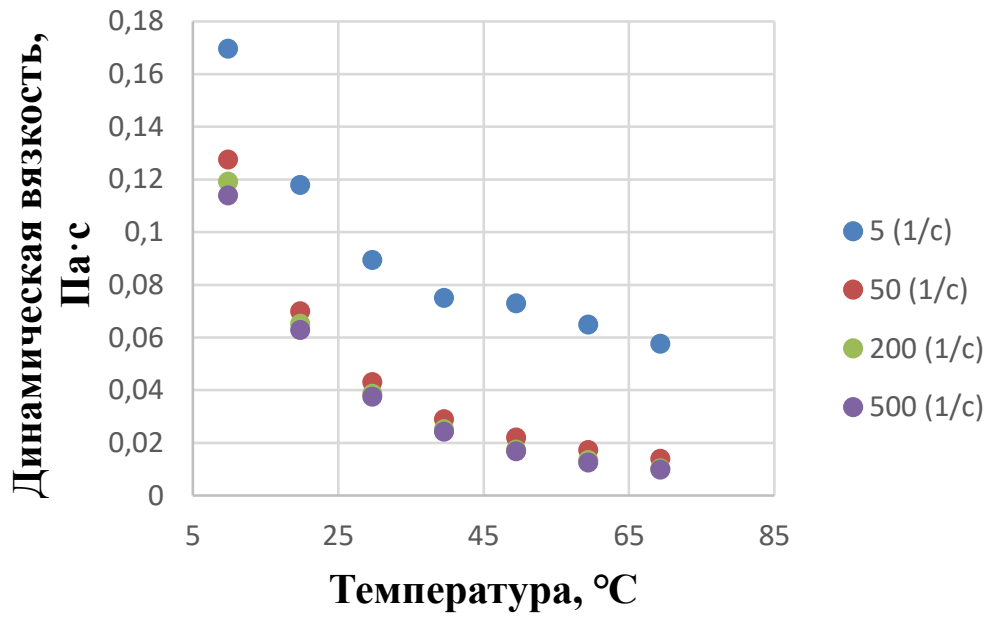

Рисунок 4 - Зависимость величины коэффиициента динамической вязкости от температуры при различных скоростях сдвига

Figure 4 - Dependence of the value of the coefficient of dynamic viscosity on temperature at different shear rates

На рисунке 5 представлена зависимость коэффрициента динамической вязкости растворов мелассы от концентрации сухих ве- ществ при температуре $30^{\circ} \mathrm{C}$. Вязкость растворов растет с увеличением концентрации СВ. 


\section{КОМПЛЕКСНЫЕ ИССЛЕДОВАНИЯ ПРОЦЕССА КУЛЬТИВИРОВАНИЯ ХЛЕБОПЕКАРНЫХ ДРОЖЖЕЙ ПРИ ВЫСОКИХ КОНЦЕНТРАЦИЯХ БИОМАССЫ. \\ 1. ИССЛЕДОВАНИЕ ФИЗИЧЕСКИХ СВОЙСТВ СВЕКЛОВИЧНОЙ МЕЛАССЫ}

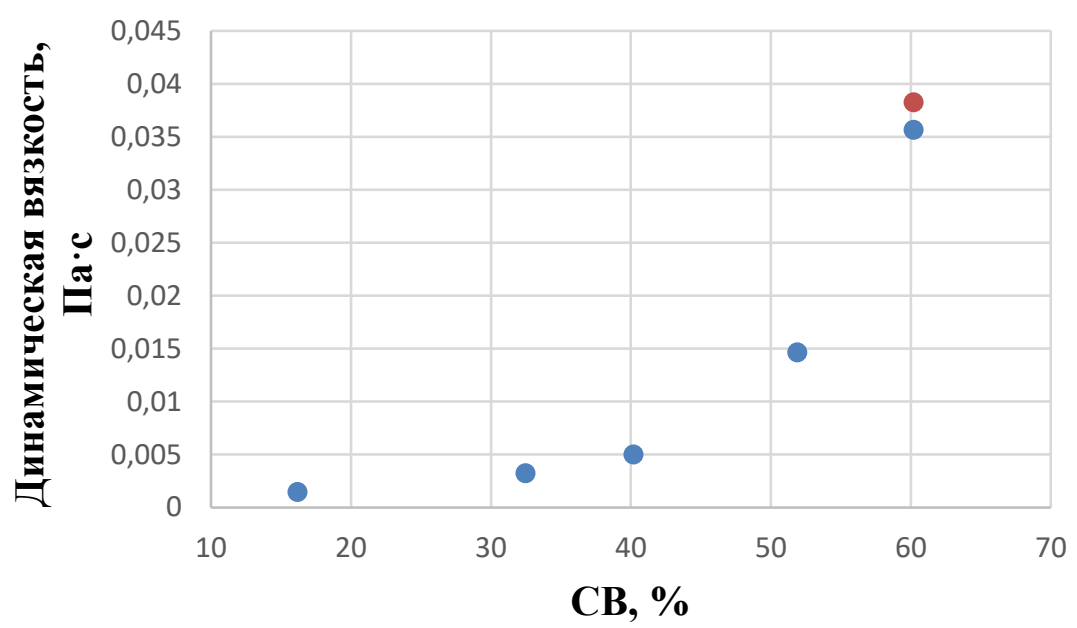

Рисунок 5 - Зависимость коэфффициента динамической вязкости растворов мелассы от концентрации сухих веществ при температуре $30^{\circ} \mathrm{C}$

Figure 5 - Dependence of the coefficient of dynamic viscosity of molasses solutions on the concentration of dry substances at a temperature of $30^{\circ} \mathrm{C}$

Этот графрик построен на основе данных, полученных в результате измерения вязкости мелассных растворов при помощи вискозиметра Гепплера. Кроме того, на график нанесена точка, характеризующая значение вязкости раствора с концентрацией 60,2 \% СВ при температуре $30^{\circ} \mathrm{C}$ и скорости сдвига $300 \mathrm{c}^{-1}$, полученная в результате измерений на ротационном вискозиметре. Таким образом, сопоставляя значения, полученные на данных приборах, можно сделать вывод, что они дают схожие, а, следовательно, достоверные результаты.

\section{ЗАКЛЮЧЕНИЕ}

На основе проведенного эксперимента проанализировали характер течения водных растворов мелассы при различном содержании сухих веществ. Получили численные значения коэфрфициентов динамической вязкости и их математической интерпретации в зависимости от варьирования температуры и концентрации СВ.

\section{СПИСОК ЛИТЕРАТУРЫ}

1. Гуляева Ю.Н. Исследование процесса культивирования хлебопекарных дрожжей при условиях высокой концентрации биомассы в кожухотрубном струйно-инжекционном фрерментаторе (КСИФ) : дисс...канд.техн.наук. СПб, СПб ГАХПТ, 1998, 153 с.

2. Новоселов А.Г. Интенсификация массообмена между газом и жидкостью и разработка высокоэффективных аппаратов для пищевой и микробиологической промышленности дисс...докт.техн.наук. 2002. СПб, СПб ГУНиПТ. 365 c.

3. Патент № 2305464 C1 РФ, МПК A23L 2/54, B01F 5/04. Кожухотрубный фрерментер с струйным впрыском: № 2006104371/15: Заявл. 13 февраля 2006 г. : опубл. 10.09.2007 / А.В. Сивенков, А.Г. Новоселов, Ю.Н. Гуляева; соискатель СанктПетербургский государственный университет низких температур и пищевых технологий.

4. Сивенков А.В., Дугнист А.В., Новоселов А.Г. Повышение эфрфективности дрожжевого производства за счет выращивания хлебопекарных дрожжей при высоких концентрациях биомассы // Хранение и переработка сельскохозяйственного сырья. 2009. № 11. C. 47-51.

5. Тишин В.Б., Новоселов А.Г., Меледина, Т.В. О скорости роста биомассы при культивировании в высококонцентрированных средах // Журнал прикладной химии. 1990. № 7. С. 1620-1621.

6. Tishin, V.B., Ismailova, Y.N. Mathematical Models of the Kinetics of the Cultivation of Microorganisms. Biophysics, 2018. V 63. № 2. P. 197-200.

7. Новоселов А.Г., Гуляева Ю.Н., Тишин В.Б., Темершин Д.Д. Энергетический обмен между клетками и питательной средой в аппарате для культивирования микроорганизмов // Низкотемпературные и пищевые технологии в XXI веке: IX Международная научно-техническая конференция, Санкт-Петербург, 13-15 ноября 2019 г. СанктПетербург : СПб. Петербургский национальный исследовательский университет информационных технологий, механики и оптики, 2019. С. 17-21.

8. Тишин В.Б., Новоселова А.Г., Анисимов С.А. Выращивание хлебопекарных дрожжей в высококонцентрированной среде // Межвузовский сборник научных трудов «Машины, агрегаты, процессы и устройства пищевой техники». Л.ЛТИХП, 1990. C. 22-27. 


\section{Е. В. КРАВЦОВА, А. Г. НОВОСЕЛОВ, А. А. ФЕДОРОВ, С. А. СОРОКИН, Е. А. ФОМИНА, О. А. СУЗДАЛЬЦЕВА}

9. Новоселов А.Г., Дужий А.Б., Голикова, Е.Ю. Дифффузия газов в жидкостях. 1. Коэфффициенты молекулярной диффузии диоксида углерода в воде. Технологии и оборудование для производства пищевых продуктов. 2014. №. 2. С. 19-25.

10. Saleem, M., Hossain, M.A., Saha, S.C., Gu Y.T. Heat transfer analysis of viscous incompressible fluid by combined natural convection and radiation in an open cavity. Mathematical Problems in Engineering. 2014. P. 141-148.

11. Сивенков А.В., Гуляева Ю.Н., Новоселов А.Г. Оценка массообменных характеристик при проектировании биосорбционных устройств для микробиологической промышленности // Вестник Международной академии холода. 2004. № 3. С. 45-47.

12. Vivian J.E., King C.J. Diffusivities of slightly soluble gases in water. A. J. Ch. E.-J. 1964. V. 10. No. 3. P. $220-221$

13. Baird M.H., Davidson J.E. Annular jets-1. Fluid dynamics. Chem. Eng. Sci. 1962. V. 17. P. 467-472.

14. Thome J.R., Cioncolini A. Introduction to two-phase flow and boiling in channels. In Encyclopedia of Two-Phase Heat Transfer and Flow. World Scientific Publishing, 2015. V. 3. P. 1-4.

15. Гаврилова А.Ю. Изучение параметров выращивания сухих хлебопекарных дрожжей из отходов сахарного производства свекольной патоки // Актуальные проблемы современной науки : сборник статей по материалам VII международной научно-практической конференции. В 3-х частях. Минск, 8 ноября 2017. Минск : Общество с ограниченной ответственностью «Дендра», 2017. С. 138143.

\section{Информация об авторах}

Е. В. Кравцова - к.т.н., преподаватель, фракультет Биотехнологий, Университет ИTMO.

А. Г. Новоселов - д.т.н., преподаватель, фракультет Биотехнологий, Университет ИTMO.

A. А. Федоров - аспирант, инженер, факультет Биотехнологий, Университет ИTMO.

C. A. Сорокин - аспирант, ассистент, факультет Энергетики и Экотехнологий, Университет ИТМО.

E. A. Фомина - студент-магистр, фракультет Биотехнологий, инженер, фракультет Энергетики и Экотехнологий, Универcumem ИТМO.

О. А. Суздальцева - студент-магистр, фракультет Биотехнологий, инженер, фракультет Энергетики и Экотехнологий, Университет.

\section{REFERENSES}

1. Gulyaeva, Yu.N. (1998). Investigation of the process of cultivation of baker's yeast under conditions of high biomass concentration in a shell-andtube jet-injection fermenter (KSIF). Candidate's thesis. $\mathrm{SPb}$. (In Russ.).

2. Novoselov, A.G. (2002). Intensification of mass transfer between gas and liquid and the development of highly efficient devices for the food and microbiological industry. Doctors thesis. St. Petersburg. (In Russ.).

3. Sivenkov, A.V., Novoselov, A.G. and Gulyaeva, Yu.N. (2007). Jet Injection Shell and Tube Fermenter Pat. 2305464 Russian Federation, publ. 09.10.2007 (In Russ.)

4. Sivenkov, A.V., Dugnist, A.V. and Novoselov A.G. (2009). Increasing the efficiency of yeast production by growing baker's yeast at high concentrations of biomass. Storage and processing of agricultural raw materials, (11), 47-51. (In Russ.).

5. Tishin, V.B., Novoselov, A.G. and Meledina, T.V. (1990). On the growth rate of biomass during cultivation in highly concentrated media. Journal of Applied Chemistry, (7),1620-1621. (In Russ.).

6. Tishin, V.B. and Ismailova, Y.N. (2018). Mathematical Models of the Kinetics of the Cultivation of Microorganisms. Biophysics, 63(2), 197-200.

7. Novoselov, A.G., Gulyaeva, Yu.N., Tishin, V.B. and Temershin, D.D. (2019). Energy exchange between cells and the nutrient medium in the apparatus for the cultivation of microorganisms. Low-temperature and food technologies in the XXI century: IX International Scientific and Technical Conference, St. Petersburg, November 13-15, 2019. St. Petersburg: St. Petersburg National Research University of Information Technologies, Mechanics and Optics. P. 17-21. (In Russ.).

8. Tishin, V.B., Novoselova, A.G. and Anisimov S.A. (1990). Cultivation of baker's yeast in a highly concentrated environment. Interuniversity collection of scientific papers "Machines, units, processes and devices of food technology". Leningra: LTIHP,P. 22-27. (In Russ.).

9. Novoselov, A.G., Duzhiy, A.B. and Golikova, E.Yu. (2014). Diffusion of gases in liquids. 1. Coefficients of molecular diffusion of carbon dioxide in water. Technologies and equipment for food production, (2), 19-25. (In Russ.).

10. Saleem, M., Hossain, M.A., Saha, S.C. and Gu, Y.T. (2014). Heat transfer analysis of viscous incompressible fluid by combined natural convection and radiation in an open cavity. Mathematical Problems in Engineering, (412480), 141-148.

11. Sivenkov, A.V., Gulyaeva, Yu.N. and Novoselov, A.G.(2004). Assessment of mass transfer characteristics in the design of biosorption devices for the microbiological industry. Bulletin of the International Academy of Cold, (3), 45-47. (In Russ.).

12. Vivian, J.E. and King, C.J. (1964). Diffusivities of slightly soluble gases in water. A. J. Ch. E.-J., 10(3), 220-221.

13. Baird, M.H. and Davidson, J.E. (1962). Annular jets-1. Fluid dynamics. Chem. Eng. Sci., (17), 467-472. 


\section{КОМПЛЕКСНЫЕ ИССЛЕДОВАНИЯ ПРОЦЕССА КУЛЬТИВИРОВАНИЯ ХЛЕБОПЕКАРНЫХ ДРОЖЖЕЙ ПРИ ВЫСОКИХ КОНЦЕНТРАЦИЯХ БИОМАССЫ. \\ 1. ИССЛЕДОВАНИЕ ФИЗИЧЕСКИХ СВОЙСТВ СВЕКЛОВИЧНОЙ МЕЛАССЫ}

14. Thome, J.R. and Cioncolini, A. (2015). Introduction to two-phase flow and boiling in channels. In Encyclopedia of Two-Phase Heat Transfer and Flow. Hackensack: World Scientific Publishing.

15. Gavrilova, A.Yu. (2017). Study of the parameters of growing dry baker's yeast from wastes of sugar beet molasses production. Actual problems of modern science: Collection of articles based on the materials of the VII international scientific and practical conference. In 3 parts, Minsk, November 8. Minsk: Limited Liability Company "Dendra", P. 138-143. (In Russ.).

\section{Information about the authors}

E. V. Kravtsova - Candidate of Technical Sciences, Lecturer, Faculty of Biotechnology, ITMO University.

A. G. Novoselov - Doctor of Technical Sciences, Lecturer, Faculty of Biotechnology, ITMO University.

A. A. Fedorov - postgraduate student, engineer, Faculty of Biotechnology, ITMO University.

S. A. Sorokin - postgraduate student, Assistant, Faculty of Energy and Ecotechnology, ITMO University.

E. A. Fomina - master's student, Faculty of Biotechnology, Engineer, Faculty of Energy and Ecotechnology, ITMO University.

O. A. Suzdaltseva - master's student, Faculty of Biotechnology, Engineer, Faculty of Energy and Ecotechnology, University.

Авторы заявляют об отсутствии конфликта интересов.

The authors declare that there is no conflict of interest.

Статья поступила в редакцию 03.06.2021; одобрена после рецензирования 12.09.2021; принята к публикации 17.09.2021.

The article was received by the editorial board on 03 June 21; approved after editing on 12 Sep 21; accepted for publication on 17 Sep 21. 